\title{
ANALISIS DAYA TARIK WISATA MINAT KHUSUS DI BALIWOSO CAMP DESA PENGOTAN KABUPATEN BANGLI
}

Ade Wani Br Purba a, 1, I Made Bayu Ariwangsa a, 2

1 adepurba62@yahoo.com, 2 bayu_ariwangsa@unud.ac.id

a Program Studi S1 Destinasi Pariwisata,Fakultas Pariwisata,Universitas Udayana, Jl. Dr. R. Goris, Denpasar, Bali 80232 Indonesia

\section{ABSTRACT}

Baliwoso camp that is located in Pengotan Village, Bangli Regency. Pengotan village has relatively cool temperature, with orange and coffee as the main commodity in this village. Baliwoso Camp presence drives the tourism in Pengotan Village, especially for special interest tourists who want to feel different sensations in his leisure. With the potiential of its tourism of Baliwoso Camp, which is closely related to the world of the campsite and to introduce local culture. Baliwoso Camp packages it in a modern way so that there is interest alone to research more deeply about the potential for special interest tourism in Baliwoso Camp.

This research will be discussed to identify the components of tourism in Baliwoso Camp with 4A concept that focuses on attraction an activity, accessibility, amenity and ancilliary. To know the potential is done by direct observation and interviews with owner of Baliwoso Camp in Pengotan Village.

With four categories of potential tourist attraction special interest in Baliwoso Camp knowable. Tourism potiential in Baliwoso Camp is natural and artificial is characteristic. With champsite atmosphere more attractive for special interest tourist. Local people who are active in Pengotan Village become one of the potential that can be developed in Baliwoso Camp. The category may also indicate the extent to which the development Baliwoso Camp both physical and non physical. It affects the local communities so that they can build a better future of Pengotan Village.

Keywords: tourism potential, atraction, accessibility, amenity, and ancilliary.

\section{PENDAHULUAN}

Kabupaten Bangli merupakan salah satu kabupaten yang terletak di Pulau Bali, identik dengan dataran tinggi dan satu-satunya kabupaten yang tidak memilki garis pantai. Desa Pengotan yang terletak di kabupaten Bangli merupakan salah satu desa yang dikenal unik karena desa ini merupaka satu-satunya desa yang melakukan nikah dan ngaben massal dengan periode waktu tertentu.

Adanya penyedia jasa wisata di Desa Pengotan akan mempermudah wisatawan untuk melakukan perjalanan wisata ke Desa Pengotan. Penyedia jasa wisata di Desa Pengotan adalah Baliwoso Camp yang berdiri sejak 2010. Hingga saat ini Baliwoso Camp telah memberikan dampak bagi masyarakat lokal terutama dalam bidang ekonomi. Potensi wisata yang dimiliki Desa Pengotan dikemas oleh Baliwoso Camp secara menarik ditambah dengan potensi wisata buatan yang dibuat oleh pengelola. Hal ini juga disertai dengan peran masyarakat lokal baik dalam pembangunan dan juga pengelolaannya.

Potensi-potensi wisata yang dimiliki Baliwoso Camp tetap mengedepankan kepentingan adat serta budaya Desa Pengotan sehingga tidak hanya mengutamakan keamanan dan kenyamanan wisatawan tetapi juga mengutamakan kepentingan masyarakat lokal. Dengan adanya analisis mengenai potensi wisata yang dimilki Baliwoso Camp sehingga dapat dikatakan potensi yang dimiliki terkhusus bagi wisatawan minat khusus. Oleh karena ini pokok permasalah dalam penelitian ini adalah apa saja potensi wisata minat khusus di Baliwoso Camp Desa Pengotan Kabupaten Bangli?

\section{KEPUSTAKAAN}

Tinjauan penelitian yang menjadi bahan perbandingan dalam penelitia ini adalah, penelitian yang dilakukan oleh Ernawati (2010) dengan judul " Tingkat Kesiapan Desa TihinganKlungkung Bali Sebagai Tempat Wisata Berbasis Masyarakat" yang membahas peran masyarakat lokal dalam mengelola potensi wisata Desa Tihingan-Klungkung.

Konsep potensi wisata merupakan acuan untuk mengetahui potensi wisata Baliwoso Camp, dimana potensi wisata merupakan sumber daya yang terdapat di sebuah daerah tertentu yang dapat dikembangkan menjadi atraksi wisata. Potensi wisata dibagi menjadi dua yaitu potensi alamiah seperti potensi fisik dan geografis, selanjutnya potensi budaya 
seperti kondisi sosial budaya, kesenian, adatistiadat dan lain sebagainya (Pendit, 1999).

Wisata minat khusus merupakan wisatawan yang memiliki permintaan di luar permintaan wisatawan lainnya. Wisatawan minat khusus biasanya memilih perjalanan wisata yang sesuai dengan latar belakang pekerjaan, hobi maupun intelektualitas. Dalam mempersiapkan layanan jasa untuk wisatawan minat khusus diperlukan perencanaan yang khusus pula, serta biaya yang di butuhkan relative lebih mahal dari pada perjalanan wisata lainnya (Marpaung, 2002)

Komponen pariwisata merupakan penggolongan potensi wisata yang dimilki Baliwoso Camp dengan konsep 4A, potensi wisata tersebut dapat dipilah menjadi atraksi dan aktivitas, aksesibilitas, amenitas dan ancilliarry atau kelembagaan (Spillane, 1994). Atraksi adalah daya tarik suatu destinasi seperti kesenian sedangkan aktivitas adalah apa saja yang dapat dilakukan wisatawan di daerah tujuan wisata.

Aksesibiltas merupakan sarana dan prasarana yang dapat memudahkan wisatawan untuk mecapai daerah tujuan wisata misalnya denah perjalanan wisata, data atraksi wisata, bandara, transportasi, waktu dan biaya yang dapat menunjang wisatawan menuju ke daerah tujuan wisata.

Amenitas merupakan fasilitas pendukung kegiatan pariwisata yang bertujuan memberikan kenyamanan terhadap wisatawan seperti akomodasi, pusat kesehatan, informasi dan komunikasi, ketersedian air bersih, listrik dan lain sebagainya.

Kelembagaan atau ancilliary merupakan komponen atau tatanan antara anggota masyarakat yang mengikat dan diwadahi oleh suatu organisasi dan merupakan sistem sosial yang melakukan usaha untuk mencapai tujuan tertentu.

\section{METODOLOGI PENELITIAN}

Penelitian ini dilakukan di Desa Pengotan Kabupaten Bangli, tepatnya di Dusun Delod Umah. Dengan membahas potensi wisata minat khusus yang dimiliki Baliwoso Camp menggunakan konsep 4A. konsep ini akan memilah komponen pariwisata di Baliwoso Camp mengenai atraksi dan aktivitas, aksesibilitas, amenitas dan kelembagaan atau ancilliary.

Data yang dipergunakan merupakan data primer yang di peroleh melalui wawancara langsung dengan pihak pengelola Baliwoso Camp, selain itu observasi langsung untuk memperoleh data juga dilakukan di Baliwoso Camp. Penelitian ini disajikan dalam bentuk deskriptif kualitatif sehingga akan memberikan gambaran mengenai potensi-potensi wisata yang dimiliki Baliwoso Camp secara keseluruhan.

\section{HASIL DAN PEMBAHASAN}

Baliwoso Camp yang terletak di Desa Pengotan berjarak $70 \mathrm{Km}$ dari bandara internasional I Gusti Ngurah Rai. Beriklim sejuk dan dingin serta identik dengan suasana pertanian, selain letak Baliwoso Camp yang berada di tengah desa juga dikelilingi oleh kebun jeruk serta kopi masyarakat lokal. Komponen potensi pariwisata minat khusus di Baliwoso Camp yang dipilah menjadi empat bagian sesuai dengan konsep 4A, atraksi dan aktivitas di Baliwoso Camp didukung oleh potensi alami dan juga potensi buatan atraksi yang dapat ditemukan di Baliwoso Camp adalah keindahan alam yang identik dengan dataran tinggi. Iklim dan cuaca di desa pengotan yang sejuk dan dingin. Adat dan kebudayaan masyarakat lokal yang unik sperti Ngaben massal. Aktivitas yang dapat dilakukan antara lain adalah:

1. Green action (kegiatan menanam pohon di Desa Pengotan, merupakan kegiatan yang wajib dilakukan wisatawan di Baliwoso Camp)

2. Amazing pengotan journey (melakukan perjalanan di Desa Pengotan baik berjalan kaki maupun bersepeda)

3. Creative, action and service (melakukan kegiatan yang kreatif serta berguna bagi masyarakat lokal dan sesama wisatawan)

4. Meeting

5. Gala dinner or romantic dinner

6. Campfire and $B B Q$

7. Cycling

8. Caldera Tour/ sunrise trekking (dilakukan pagi hari di sekitaran Gunung Batur, Kintamani) 
Aksesibilitas di Baliwoso Camp sudah cukup baik secara fisik dan non fisik. Secara fisik khususnya jalan menuju Baliwoso Camp dilengkapi dengan jalan beraspal, adanya papan penunjuk arah di beberapa titik mengingat Baliwoso Camp terletak di tengah Desa Pengotan yang berada di antara ladang dan kebun masyarakat lokal. Aksesibilitas non fisik yaitu aksesibilitas yang dapat dinilai dari segi sosial, sampai saat ini aksesibilitas sosial di Baliwoso Camp sangat baik terlihat bagaimana terbukanya masyarakat lokal dengan adanya pembangunan pariwisata di Desa Pengotan. Keramah-tamahan dan penerimaan masyarakat lokal terhadap wisatawan merupakan salah satu aksesibilitas sosial di Baliwoso Camp.

Amenitas atau fasilitas di Baliwoso Camp identik dengan perkemahan fasilitas yang dimiliki baliwoso camp yaitu:

1. Sleeping tend (bangunan tenda semi permanen yang berjumlah 11 tenda, dilengkapi dengan kasur, bantal, selimut, listrik dan juga air mineral)

2. Communal tend (tenda yang berukuran besar biasa digunakan sebagai tempat menimati makanan breakfast, lunch or dinner dan juga sebagai tempat pertemuan)

3. Playground (arena bermain bagi wisatawan di lengkapi dengan permainan tradisional maupun modern)

4. Bale woso (bangunan semi permanen yang sering digunakan untuk menyambut wisatawan, tempat meeting, juga sering digunakan sebagai camp fire and BBQ jika cuaca pada malam hari tidak mendukung)

5. Stage (panggung terbuka yang digunakan pada malam hari untuk memepertontonkan hiburan atau suatu acara yang dipersembahkan masyarakat desa pengotan yang berkolaborasi dengan wisatawan)

6. Hot and cold water (komponen yang terpenting selain toilet mengingat cuaca di desa pengotan yang sejuk dan dingin).

Kelembagaan atau ancilliary di Baliwoso Camp Desa Pengotan di kelola oleh investor dari
Jakarta, untuk direktur utama ada Bapak Irwan, Finance atau keuangan Bapak Edi, sedangkan manager camp adalah masyarakat lokal yaitu bapak Bayer. Untuk bagian lainnya juga di tempati oleh masyarakat lokal seperti mechanical and electrical Bapak Raca, housekeeping Bapak Sadar dan Kardi, Games and properties Bapak Gede dan Nick dan food and beverage Bapak Kobong. Dengan adanya struktur organisasi memudahkan para penyedia jasa wisata untuk melakukan tugasnya sesuai ketentuan. Selain itu kelembagaan di Baliwoso Camp menjadi media bagi masyarakat untuk belajar terutama dalam menyediakan jasa wisata bagi wisatawan minat khusus.

\section{SIMPULAN DAN SARAN}

\subsection{Simpulan}

Potensi wisata minat khusus di Baliwoso Camp dapat di kategorikan potensi alami dan buatan. Potensi alami yang memang sudah ada di desa pengotan iklim dan cuaca sejuk khas pegunungan, adat dan budaya desa pengotan juga menjadi potensi yang besar di Baliwoso Camp. Potensi buatan yang disiapkan oleh pengelola di sesuaikan dengan kondisi dan suasana perkemahan. Kelembagaan di Baliwoso Camp didukung oleh aktifnya masyarakat lokal menjadi penanggung jawab di beberapa bagian dalam kelembagaan tersebut.

\subsection{Saran}

Rekomendasi dalam meningkatkan potensi wisata minat khusus di Baliwoso Camp adalah semakin meningkatkan peran masyarakat Desa Pengotan secara keseluruhan dalam memberikan pelayanan jasa pariwisata terutama dalam meningkatkan potensi wisata di Baliwoso Camp.

\section{DAFTAR PUSTAKA}

Eriantari. 2013. Analisis Potensi Atraksi Desa Pengotan Dalam Kerangka Pembangunan Pariwisata Berbasis Masyarakat Melalui Dukungan Baliwoso Camping Site. Laporan Akhir, Yogyakarta: Program Studi Pariwisata Universitas Gajah Mada.

Ernawati. 2013. Tingkat Kesiapan Desa Tihingan-Klungkung Bali Sebagai Tempat Wisata Berbasis Masyarakat Jurnal Pariwisata, Denpasar: Analisis Pariwisata.

Kusmayadi dan Endar Sugiarto. 2000. Metodologi Penelitian Dalam Bidang Kepariwisataan. Jakarta: PT. Gramedia Pustaka.

Marpaung, Happy. 2002. Pengetahuan Pariwisata. Bandung: Alfabeta 
Vol. 4 No 2, 2016

Pendit. 1986. Ilmu Pariwisata Sebuah Pengantar Perdana. Jakarta: PT. Pradnya Paramita. Cetakan Ketiga.

Spillane, James J. 1994. Pariwisata Indonesia Siasat Ekonomi dan Rekayasa Kebudayaan. Yogyakarta: Kanisius.

Sugiyono. 2014. Metode Penelitian Kuantitatif Kualitatif dan $R \& D$. Bandung: Alfabeta.

Wardiantara. 2006. Metode Penelitian Pariwisata. Yogyakarta ANDI. 